\title{
Triacylglycerol Production from Corn Stover Using a Xylose-Fermenting Rhodococcus opacus Strain for Lignocellulosic Biofuels
}

\author{
Kazuhiko Kurosawa1, Sandra J Wewetzer ${ }^{3}$ and Anthony J Sinskey ${ }^{1,2 *}$
}

${ }^{1}$ Department of Biology, Massachusetts Institute of Technology, 77 Massachusetts Avenue, Cambridge, MA 02139, USA

${ }^{2}$ Engineering Systems Division, Massachusetts Institute of Technology, 77 Massachusetts Avenue, Cambridge, MA 02139, USA

${ }^{3}$ Department of Biochemical Engineering, RWTH Aachen University, Worringerweg 1, 52074 Aachen, Germany

\begin{abstract}
Triacylglycerols (TAGs) are in the spotlight as a feasible source of hydrocarbon-based biofuels. Rhodococcus opacus PD630 produces large amounts of intracellular TAGs in cultivations containing high concentrations of glucose, but it does not utilize xylose present in all hydrolysates of lignocellulosic biomass. We constructed a highpotency xylose-fermenting $R$. opacus strain MITXM-61 that exhibited robust growth and TAG biosynthesis on high concentrations of xylose by activating potential xylose-metabolism genes. MITXM- 61 had the uncommon capacity to grow in defined media supplemented with xylose at concentrations of greater than $200 \mathrm{gl}^{-1}$. MITXM-61 grown in corn stover hydrolysates containing $118 \mathrm{gl}^{-1}$ of initial total sugars was capable of completely and simultaneously utilizing both xylose and glucose in the genuine lignocellulosic feedstock, and yielded $15.9 \mathrm{gl}^{-1}$ of TAGs, corresponding to $54 \%$ of the cell dry weight. The oleaginous bacterium $R$. opacus strain proved useful for developing a new manufacturing paradigm to generate advanced lignocellulosic biofuels.
\end{abstract}

Keywords: Triacylglycerol; Rhodococcus opacus; Xylose; Corn stover; Lignocellulosic biofuel

\section{Introduction}

Advanced biofuels from renewable sources have been recognized as a potential solution for the interrelated issues of energy sustainability and environmental protection [1,2]. Advanced biofuels can be generally divided into two categories: alcohol-based fuels, such as ethanol and butanol, and hydrocarbon-based fuels, including gasoline, diesel and jet fuel. Bioethanol has been widely regarded as a successful alternative liquid fuel, but it has some drawbacks, such as its low energy density and incompatibility with the existing fuel infrastructure $[3,4]$. Hydrocarbon-based biofuels are converted from triacylglycerols (TAGs), esters in which three fatty acid molecules are linked to glycerol [5]. Over the years, technology for producing hydrocarbon-based biofuels that are identical in virtually every respect to commercially available petroleum-derived fuels has been developed [6,7]. Recently, the renewable jet fuel, termed hydroprocessed esters and fatty acids (HEFA), made from vegetable TAGs-containing feedstocks, such as camelina and jatropha have been successfully tested in commercial and military aircrafts, and have been approved by the world's standard body (ASTM D7566) for use in commercial flights $[2,8,9]$. Presently, however, renewable fuels are significantly more expensive than conventional petroleum-derived fuel, and should be produced from sustainable lignocellulosic biomass resources to preclude "food versus fuel" concerns [2,7]. TAGs are found ubiquitously as major carbon storage molecules in plants, animals, algae and microorganisms $[10,11]$. Although algae have been explored as a renewable source for lipid-based fuels owing to the ability to produce substantial amounts of TAGs, it is considered that commercial-scale production of biofuels from algae is incompatible with existing technologies $[12,13]$. Oleaginous microbes that utilize a wider variety of substrates provide opportunities for TAG production from lignocellulosic biomass [14]. Nevertheless, microbial technologies for efficiently converting lignocellulosic biomass to sustainable biomaterials and biofuels have not yet been established $[15,16]$. One of the vital challenges is efficient fermentations of the sugar mixtures, which contain glucose and xylose as major components, present in all hydrolysates of lignocellulosic biomass [17-21].
Rhodococcus opacus PD630, an oleaginous hydrocarbon-degrading bacterium, is able to utilize a wider variety of substrates and accumulate intracellular TAGs consisting primarily of C16 and C18 series long chain fatty acids, which are quite similar to those of vegetable-based TAGs, in excess of $70 \%$ of their dry cell weight during cultivation under nitrogen-limiting conditions [22]. Bacterium can produce large amounts of TAGs in batch-cultivation containing high concentrations of glucose [23]. However, wild-type R. opacus PD630 does not utilize xylose. We have recently enabled xylose metabolism in $R$. opacus PD630 by expressing heterologous xylA and xylB genes derived from Streptomyces padanus [24].

Corn stover and switchgrass are the two most widely explored lignocellulosic biomass feedstocks for commercial production of advanced biofuels [25-28]. Switchgrass is recognized as a desirable energy crop due to high productivity, low agricultural inputs for harvest, and protection of the environment [29]. Corn stover, consisting of stalks, cobs and leaves that remain in fields after the gain harvest, has a carbohydrate content of approximately $60 \%$ of the dry weight [30]. Since corn stover is an abundant agricultural residue in areas of large-scale corn production, it has been a model feedstock for biofuels process development research [31]. It is anticipated that over 100 million tons of corn stover in the U.S. could be collected annually without causing excessive soil erosion, although corn stover removal strategies that minimize the potential impacts on soil quality and sustainability have to be developed [32,33]. In this study, we have

*Corresponding author: Anthony J. Sinskey, Department of Biology, Massachusetts Institute of Technology, Room 68-370, 77 Massachusetts Avenue Cambridge, MA 02139, USA, Tel: +1-617-253-6721; Fax: +1-617-253-8550; E-mail: asinskey@mit.edu

Received May 02, 2014; Accepted June 04, 2014; Published June 11, 2014

Citation: Kurosawa K, Wewetzer SJ, Sinskey AJ (2014) Triacylglycerol Production from Corn Stover Using a Xylose-Fermenting Rhodococcus opacus Strain for Lignocellulosic Biofuels. J Microb Biochem Technol 6: 254-259. doi:10.4172/19485948.1000153

Copyright: (c) 2014 Kurosawa K, et al. This is an open-access article distributed under the terms of the Creative Commons Attribution License, which permits unrestricted use, distribution, and reproduction in any medium, provided the original author and source are credited 
succeeded in constructing a more high-potency xylose-fermenting strain MITXM-61 by activating potential xylose-metabolism genes of $R$. opacus PD630 using an adaptive evolution strategy, and have investigated the fermentative production of TAGs by the constructed strain on corn stover hydrolysate.

\section{Materials and Methods}

\section{Biomass, enzymes and chemicals}

Ensiling corn stover was kindly provided by Sweetwater Energy Inc. (Rochester, NY). The corn stover contained 39\% glucan, $19 \%$ xylan, and $16 \%$ lignin on a dry weight basis. Cellic CTec2 (a blend of aggressive cellulases, high level of $\beta$-glucosidases and hemicellulase) was purchased from Novozymes North America Inc. (Franklinton, NC). LB broth was purchased from BD Diagnostic Systems (Sparks, MD). All other chemicals were obtained from Sigma-Aldrich (St. Louis, MO) unless otherwise noted.

\section{Bacterial strains and media}

R. opacus PD630 (DSM 44193) was obtained from the Deutsche Sammlung von Mikroorganismen und Zellkulturen GmbH (DSMZ, Germany). R. opacus Xsp8C was from previous study [24], and $R$. opacus MITXM-61 was constructed in this study and deposited with the ATCC patent depository having the number PTA-12196. The culture media used were LB broth and a phosphate-buffered defined medium. The defined medium contained per liter: $16 \mathrm{~g}$ xylose, $1.0 \mathrm{~g}\left(\mathrm{NH}_{4}\right)_{2} \mathrm{SO}_{4}$ and mineral components consisted of $1.0 \mathrm{~g} \mathrm{MgSO}_{4} \cdot 7 \mathrm{H}_{2} \mathrm{O}, 0.015 \mathrm{~g}$ $\mathrm{CaCl}_{2} \cdot 2 \mathrm{H}_{2} \mathrm{O}, 1.0 \mathrm{ml}$ of a trace element solution, $1.0 \mathrm{ml}$ stock A solution, and $35.2 \mathrm{ml} 1.0 \mathrm{M}$ phosphate buffer as described [24]. Modifications of the defined medium are stated in figure legends. Solid media were supplemented with $2 \%$ agar. The strains were routinely maintained on LB agar medium and preserved in $20 \%(\mathrm{v} / \mathrm{v})$ glycerol at $-80^{\circ} \mathrm{C}$

\section{Cultivations}

R. opacus strains were grown at $30^{\circ} \mathrm{C}$. Cell growth was measured by the optical density (OD) at $660 \mathrm{~nm}$ (Thermo Scientific GENESYS 20, Waltham, MA) or the cell dry weight (CDW). Cultures were inoculated with a seed culture to an initial OD of $1.0\left(2.5 \times 108 \mathrm{cfu} \mathrm{ml}^{-1}\right)$. Shake flask experiments were carried out using $250 \mathrm{ml}$ baffled flasks containing 50 $\mathrm{ml}$ of defined medium, and incubated on a rotary shaker at $200 \mathrm{rpm}$ (Multitron, Infors, Bottmingen, Switzerland). Fermentor experiments were carried out in a $500 \mathrm{ml}$ fermentor (Sixfors bioreactor, Infors) with a working volume of $300 \mathrm{ml}$ or a 2 liter fermentor (Bioengineering bioreactor, R'ALF, Wald, Switzerland) with a working volume of 1 liter. The $\mathrm{pH}$ of the medium was maintained at $6.9 \pm 0.1$ by the automatic addition of $2 \mathrm{M} \mathrm{NaOH}$. Dissolved oxygen was measured with an Ingold polarographic probe (Mettler-Toledo Ingold Inc., Bedford, MA). To guarantee optimal growth, the dissolved oxygen tension was maintained above $60 \%$ by manually adjusting the agitation speed from $300 \mathrm{rpm}$ up to $1000 \mathrm{rpm}$ and automatically sparging with a mixture of air and pure oxygen at a constant gas flow rate of $1.0 \mathrm{VVM}$. When necessary, polypropylene glycol P 2000 was manually added to each vessel to prevent foam formation. To prepare the seed culture, a loopful of cells from colonies grown on a LB agar plate for 3 days was grown in a defined medium in a flask for 2 days.

\section{Strain construction}

Electrocompetent cells of R. opacus Xsp8C, a spontaneous plasmidcured strain (non-xylose-fermenting) of Xsp 8 carrying exogenous genes of xylA and xylB on the plasmid (pXsp8), were prepared, as previously described [24]. Seventy-five microliters of the competent cells (OD660 of 50) of Xsp8C were pipetted into a $2 \mathrm{~mm}$ electroporation cuvette (VWR, Radnor, PA) and treated with a gene pulser (Bio-Rad, Hercules, CA) at settings of $2.5 \mathrm{kV}, 25 \mu \mathrm{F}$ and $200 \Omega$. Pulsed cells were diluted with $300 \mu \mathrm{l}$ of LB broth, regenerated for $3 \mathrm{~h}$ with gentle agitation, plated onto the defined agar medium containing xylose as a sole carbon source and incubated to harbor xylose utilizing strains. After 14 days of cultivation, a spontaneous mutant that exhibited robust growth on xylose was isolated, and termed strain MITXM-61.

\section{Response surface methodology}

The statistical approach using a Box-Wilson central composite design with five levels for each of two factors was applied to optimize the operational $\mathrm{C} / \mathrm{N}$ ratio of defined medium for maximum production of TAGs in submerged batch fermentations [24]. A set of 11 experiments was carried out with nine combinations of xylose and $\left(\mathrm{NH}_{4}\right)_{2} \mathrm{SO}_{4}$ concentrations with a central point to be run in triplicate. The design matrix of the experimental conditions was subjected to regression analysis by using the software StatGraphics (StatPoint Inc., USA). Three-dimensional response surface curves were plotted by SigmaPlot 11 (Systat Software, Inc., San Jose, CA) to display the interaction among various variables.

\section{Analytical methods}

The CDW was determined by lyophilizing cell pellet after centrifuging $10 \mathrm{ml}$ of culture broth at $8,000 \mathrm{~g}$ for $15 \mathrm{~min}$ and washing the cell pellet twice in deionized water. The lyophilized cell pellet was used to analyze the fatty acids of TAGs. To determine the fatty acid content of the cells and the composition of lipids, fatty acids were converted to methyl esters by methanolysis followed by gas chromatography-flame ionization detector (GC-FID) analysis as previously described [24]. The fatty acids were identified and quantified by comparison to standard FAMEs. Fatty acid content was defined as the percentage of the ratio of fatty acids to cell dry weight (\% CDW). Sugars in the culture and the corn stover hydrolysates were measured by high-performance liquid chromatography (HPLC, Agilent 1100 system) fitted with an Aminex HPX- $87 \mathrm{H}$ column $(300 \times 7.8 \mathrm{~mm}$, BIO-RAD) coupled to a refractive index (RI) detector as previously described. Total sugar concentrations were estimated as reducing sugar equivalents by the dinitrosalicylic acid method. Ammonia concentrations in the culture and protein concentrations of the enzyme were determined by the Sigma Ammonia Assay Kit and the Bio-Rad Protein Assay Kit II (Hercules, CA), respectively, according to the manufacturer's instructions. Glucan, xylan, lignin and moisture contents (as a percentage) of ensiling corn stover were estimated using the National Renewable Energy Laboratory protocol [34]. The moisture content was determined by drying the sample at $105^{\circ} \mathrm{C}$. In this analysis, acid hydrolysis is used to hydrolyse the material into monomeric sugars. Klason lignin was determined as the acid-insoluble residue from acid hydrolysis.

\section{Preparation of corn stover hydrolysate}

Ensiling corn stover (Figure 4a) was used as the raw material, and the sizes of pieces were $5 \mathrm{~mm}$ to $30 \mathrm{~mm}$ in length and $1 \mathrm{~mm}$ to $5 \mathrm{~mm}$ in thickness. The moisture content was $70 \%$ (total weight basis). Alkali treatment was performed on ensiling corn stover before hydrolysis. The raw biomass at a solid: liquid ratio of $0.2 \mathrm{~g} \mathrm{ml}^{-1}\left(0.06 \mathrm{~g} \mathrm{ml}^{-1}\right.$ dry basis) was soaked in $1 \%(\mathrm{w} / \mathrm{v}) \mathrm{NaOH}$ solution in glass bottles and incubated at $90^{\circ} \mathrm{C}$ in a heating bath (Buchi B-490, Marshall Scientific, Brentwood, $\mathrm{NH}$ ). After $45 \mathrm{~min}$ of duration, the pretreatment liquor was vacuum filtered through a Buchner funnel and the pretreated biomass 
Citation: Kurosawa K, Wewetzer SJ, Sinskey AJ (2014) Triacylglycerol Production from Corn Stover Using a Xylose-Fermenting Rhodococcus opacus Strain for Lignocellulosic Biofuels. J Microb Biochem Technol 6: 254-259. doi:1.4172/1948-5948.1000153

recovered by filtration was resuspended in the same volume of a fresh $1 \% \mathrm{NaOH}$ solution, and kept at $90^{\circ} \mathrm{C}$ for an additional $45 \mathrm{~min}$. The alkali-treated biomass was filtered, and the remaining solid biomass was washed three times with deionized water $\left(5 \mathrm{mlg}^{-1}\right.$ raw biomass) to remove the soluble components and to neutralize the substrate. The washed residue was dried at $60^{\circ} \mathrm{C}$ overnight in an oven (Figure $4 \mathrm{~b}$ ) and ground into fine particles using a Laboratory Blender $(7010 \mathrm{G}$, Waring commercial) for $5 \mathrm{~min}$, resulting in fiber particles with the width of 0.1 $\mathrm{mm}$ to $1 \mathrm{~mm}$ and the length of $0.1 \mathrm{~mm}$ to $10 \mathrm{~mm}$ (Figure $4 \mathrm{c}$ ). A total of $1.06 \mathrm{~kg}$ of the powdered material from $2 \mathrm{~kg}$ of ensiling corn stover (dry basis) based on the above-mentioned procedure was obtained.

Hydrolysis of the pretreated corn stover was carried out in a rotary shaker (Multitron, Infors, Bottmingen, Switzerland) at $45^{\circ} \mathrm{C}$ and 200 $\mathrm{rpm}$ for $48 \mathrm{~h}$. One hundred grams of the pretreated material and 10 $\mathrm{g}$ of CTec2 enzyme cocktail (a density of $1.23 \mathrm{gml}^{-1}, 83 \mathrm{mg}$ protein $\mathrm{ml}^{-1}$ ) was mixed with $890 \mathrm{ml}$ of a $0.002 \mathrm{~N} \mathrm{HCl}$ solution in a 2 liter flask. The suspension was adjusted to $\mathrm{pH} 5.0$ with $0.1 \mathrm{~N} \mathrm{HCl}$ and volume to $1000 \mathrm{ml}$ with deionized water. Additionally, the pretreated material was added as a double bolus dose $(50 \mathrm{~g}$ each after $3 \mathrm{~h}$ and $6 \mathrm{~h}$ of duration). After hydrolysis, the mixture was centrifuged twice at 8,000 $\mathrm{g}$ for $20 \mathrm{~min}$ to remove solid particles, and the supernatant was used for subsequent fermentation.

\section{Results and Discussion}

\section{Growth of $R$. opacus MITXM-61 with high xylose concentrations}

High-cell-density cultivation is a prerequisite to maximize volumetric productivity and minimize the cost of microbial fermentations, and the feedstocks used should typically be composed of highly concentrated sugars [35]. The growth kinetics of R. opacus MITXM-61 were examined in defined media with initial xylose concentrations of $40,120,160,180,200$ or $220 \mathrm{gl}^{-1}$ in flask cultures (Figure 1). MITXM-61 started growing in media containing up to 120 $\mathrm{gl}^{-1}$ of xylose after 1 day of cultivation and was able to grow on media containing greater than $200 \mathrm{gl}^{-1}$ xylose within 3 days post-inoculation. The growth of MITXM-61 was observed in media containing higher concentrations of xylose and exhibited a significantly shorter lag phase in comparison with that of Xsp8 engineered in previous study [24].

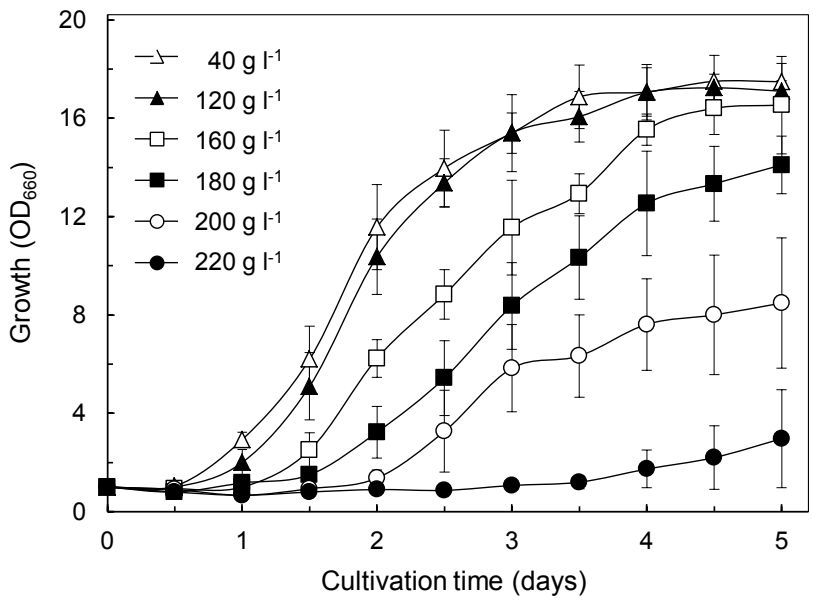

Figure 1: Growth of $R$. opacus MITXM-61 on varying concentrations of xylose. The strain was grown in defined media with different xylose concentrations of $40,120,160,180,200$ and $220 \mathrm{gl}^{-1}$ in flasks. Values and error bars represent the mean and s.d. of triplicate experiments.

\section{Optimization of TAG production from xylose by $R$. opacus MITXM-61}

Maximum production of TAGs from xylose by MITXM-61 was predicted using a response surface methodology. TAG production in $R$. opacus is heavily influenced by the ratio of carbon to nitrogen $(\mathrm{C} / \mathrm{N})[23]$. The critical operational $\mathrm{C} / \mathrm{N}$ ratio of xylose and $\left(\mathrm{NH}_{4}\right)_{2} \mathrm{SO}_{4}$ in the defined medium was optimized using the design model that determined nine combinations of xylose and $\left(\mathrm{NH}_{4}\right)_{2} \mathrm{SO}_{4}$ concentrations with a central point to be run in triplicate for a total of 11 bioreactors. MITXM-61 was found to grow and accumulate TAGs even at a concentration of $240 \mathrm{gl}^{-1}$ xylose in the bioreactor culture (Figure 2a), although the growth of the strain was poor on $220 \mathrm{gl}^{-1}$ xylose in flask cultures (Figure 1). The software StatGraphics derived the following model equation in terms of actual values:

$$
\mathrm{Y}=-6.16735+0.155388 \mathrm{X}_{1}+2.58303 \mathrm{X}_{2}-0.000790207 \mathrm{X}_{12}+0.00994511 \mathrm{X}_{1} \mathrm{X}_{2}-
$$
$0.216121 \mathrm{X}_{22}$

where $\mathrm{Y}$ is the TAG production $\left(\mathrm{gl}^{-1}\right)$ as fatty acids, and $\mathrm{X}_{1}$ and $\mathrm{X}_{2}$ are the concentrations $\left(\mathrm{gl}^{-1}\right)$ of xylose and $\left(\mathrm{NH}_{4}\right)_{2} \mathrm{SO}_{4}$, respectively. The surface plot illustrated by the equation using the SigmaPlot 11 is presented (Figure $2 \mathrm{~b}$ ). The experimental design predicted that growing MITXM-61 cells in a defined medium with a $\mathrm{C} / \mathrm{N}$ ratio of 16.5 containing $159 \mathrm{gl}^{-1}$ xylose and $9.63 \mathrm{gl}^{-1}\left(\mathrm{NH}_{4}\right)_{2} \mathrm{SO}_{4}$ would result in a maximal TAG production of $18.6 \mathrm{gl}^{-1}$ as fatty acids. The predicted yield was demonstrated by batch-culture fermentations with the optimized conditions. The accumulation of TAGs in this case was $16.9 \mathrm{gl}^{-1}$, corresponding to $43 \%$ of the CDW, which was close to the predicted yield (Figure $2 \mathrm{c}$ ).

\section{TAG production of $R$. opacus MITXM-61 on a mixture of xylose and glucose}

Total sugars from corn stover hydrolysates generally contain $25-35 \%$ xylose [36]. We also investigated TAG production of strain MITXM-61 on mixed sugars in a 2-to-1 glucose/xylose mixture. The cells of MITXM-61 were inoculated into a modified defined medium containing $40 \mathrm{gl}^{-1}$ xylose and $80 \mathrm{gl}^{-1}$ glucose in batch cultures (Figure 3 ). The cells started growing after $8 \mathrm{~h}$ of cultivation, and nitrogen depletion occurred between 1 and 2 days. Glucose was completely depleted after 2 days and xylose after 3 days with the concomitant consumption of xylose and glucose in the medium. After 2 days of cultivation, 14.1 $\mathrm{gl}^{-1}$ TAGs as fatty acids were produced, which result in a productivity of $0.294 \mathrm{gl}^{-1} \mathrm{~h}^{-1}$. The maximum production of TAGs was $15.8 \mathrm{gl}^{-1}$, corresponding to $54.7 \%$ of the CDW $\left(28.9 \mathrm{gl}^{-1}\right)$, which occurred after 3 days of cultivation.

\section{Fermentation of $R$. opacus MITXM-61 on corn stover hydrolysate}

We next explored the impact of TAG production by $R$. opacus MITXM-61 on corn stover hydrolysate. It is known that ensiling corn stover is able to preserve large quantities of feedstock from seasonally harvested fields and the corn stover has a high carbohydrate content allowing for easy degradation [37]. We used the ensiling biomass as a feedstock for the TAG production. The raw biomass was $\mathrm{NaOH}$-treated and milled to fiber particles with a width of $0.1 \mathrm{~mm}$ to $1 \mathrm{~mm}$ and a length of $0.1 \mathrm{~mm}$ to $10 \mathrm{~mm}$ for efficiently saccharifying the material with enzymatic treatment (Figure 4c). The pretreated material (total amount of $200 \mathrm{gl}^{-1}$ ) was hydrolyzed with a commercial enzyme (Cellic $\mathrm{CTec} 2$ ) at $\mathrm{pH} 5.0$ and $45^{\circ} \mathrm{C}$. An initial quick enzymatic hydrolysis step occurred in the first $12 \mathrm{~h}$ and the released sugar after $48 \mathrm{~h}$ was $131 \mathrm{gl}^{-1}$ 
Citation: Kurosawa K, Wewetzer SJ, Sinskey AJ (2014) Triacylglycerol Production from Corn Stover Using a Xylose-Fermenting Rhodococcus opacus Strain for Lignocellulosic Biofuels. J Microb Biochem Technol 6: 254-259. doi:1.4172/1948-5948.1000153

(a)

\begin{tabular}{|c|c|c|c|c|c|}
\hline \multirow{2}{*}{ Run } & \multicolumn{2}{|c|}{ Real values } & \multicolumn{2}{|c|}{ Coded values } & \multirow{2}{*}{$\begin{array}{c}\text { Fatty acid } \\
\text { production }\left(\mathrm{gl}^{-1}\right)\end{array}$} \\
\hline & $\mathrm{X}_{1}$ & $X_{2}$ & $x_{1}$ & $X_{2}$ & \\
\hline 1 & 120.0 & 7.5 & 0 & 0 & 17.4 \\
\hline 2 & 35.1 & 2.2 & -1 & -1 & 4.4 \\
\hline 3 & 120.0 & 7.5 & 0 & 0 & 18.2 \\
\hline 4 & 240.0 & 7.5 & 1.41 & 0 & 7.7 \\
\hline 5 & 35.1 & 12.8 & -1 & 1 & 2.4 \\
\hline 6 & 120.0 & 7.5 & 0 & 0 & 16.2 \\
\hline 7 & 204.9 & 12.8 & 1 & 1 & 19.6 \\
\hline 8 & 204.9 & 2.2 & 1 & -1 & 3.7 \\
\hline 9 & 0.0 & 7.5 & -1.41 & 0 & 0.0 \\
\hline 10 & 120.0 & 15.0 & 0 & 1.41 & 6.2 \\
\hline 11 & 120.0 & 0.0 & 0 & -1.41 & 0.0 \\
\hline
\end{tabular}

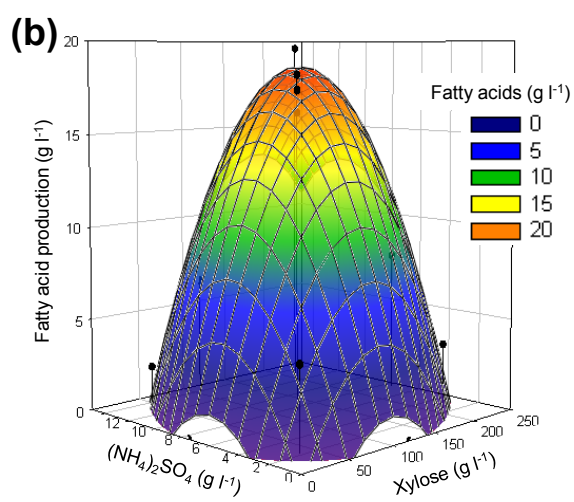

(c)
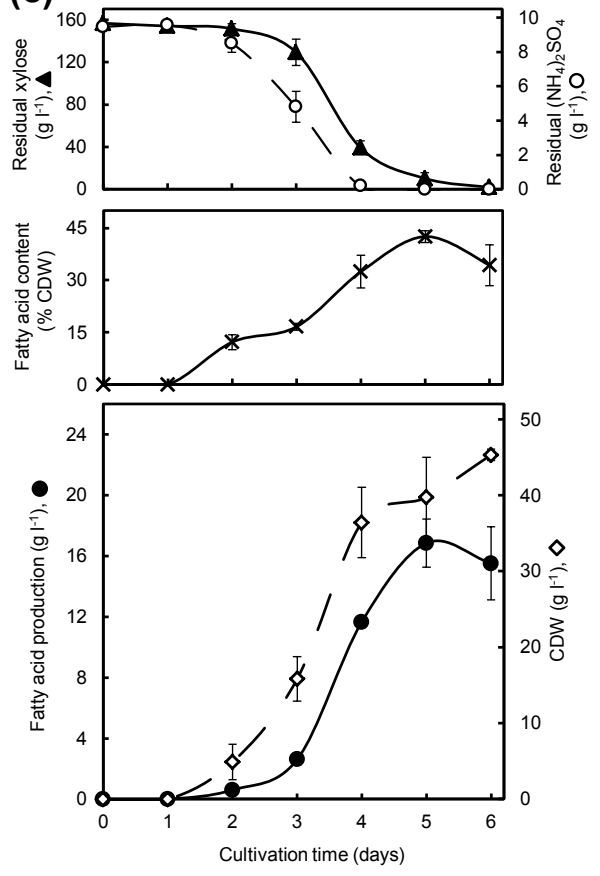

Figure 2: Optimization of TAG production from xylose by $R$. opacus MITXM-61 in batch-culture fermentations. (a) Central composite experimental design matrix defined xylose and $\left(\mathrm{NH}_{4}\right)_{2} \mathrm{SO}_{4}$ concentrations. $\mathrm{X} 1$, xylose concentration $\left(\mathrm{gl}^{-1}\right) ; \mathrm{X} 2,\left(\mathrm{NH}_{4}\right)_{2} \mathrm{SO}_{4}$ concentration $\left(\mathrm{gl}^{-1}\right)$. The strain was grown in modified defined media containing various concentrations of xylose and $\left(\mathrm{NH}_{4}\right)_{2} \mathrm{SO}_{4}$ in Sixfors-bioreactors. The data for TAG production as fatty acids represent the maximum values during 10 days of cultivation. (b) Response surface plot of the effect of xylose and ( $\left.\mathrm{NH}_{4}\right)_{2} \mathrm{SO}_{4}$ concentrations on fatty acid production. Curves and points represent predicted values and experimental data, respectively. (c) Time course of fatty acid production carried out under the optimized growth

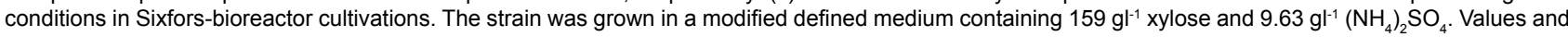
error bars represent the mean and s.d. of triplicate experiments.

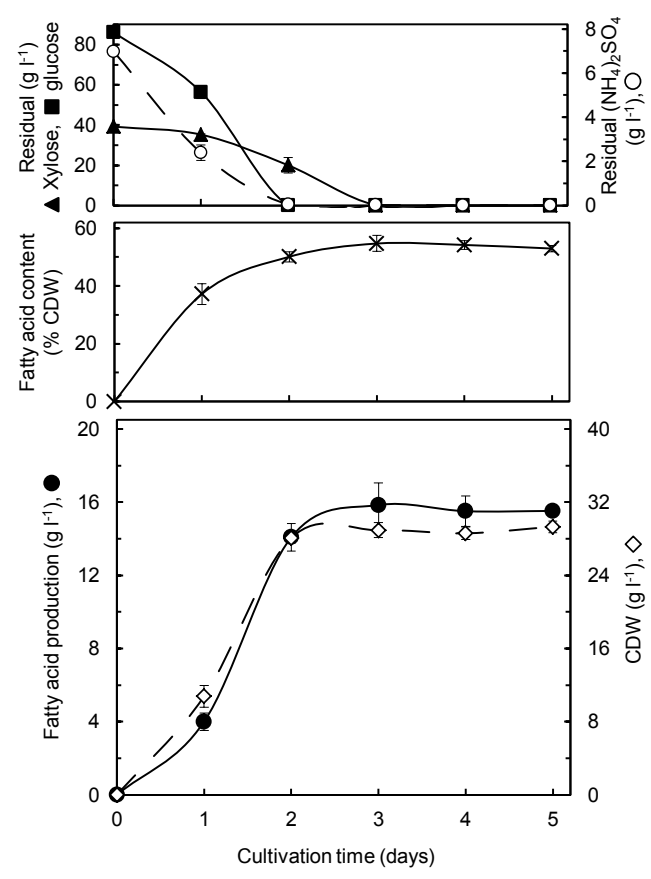

Figure 3: Time course of TAG production by $R$. opacus MITXM-61 on a mixture of xylose and glucose in batch-culture fermentations. The strain was grown in a modified defined medium containing $40 \mathrm{gl}^{-1}$ xylose, $80 \mathrm{gl}^{-1}$ glucose and $7.06 \mathrm{gl}^{-1}$ $\left(\mathrm{NH}_{4}\right)_{2} \mathrm{SO}_{4}$ in the Bioengineering-bioreactor cultivations. Values and error bars represent the mean and s.d. of triplicate experiments. (a)

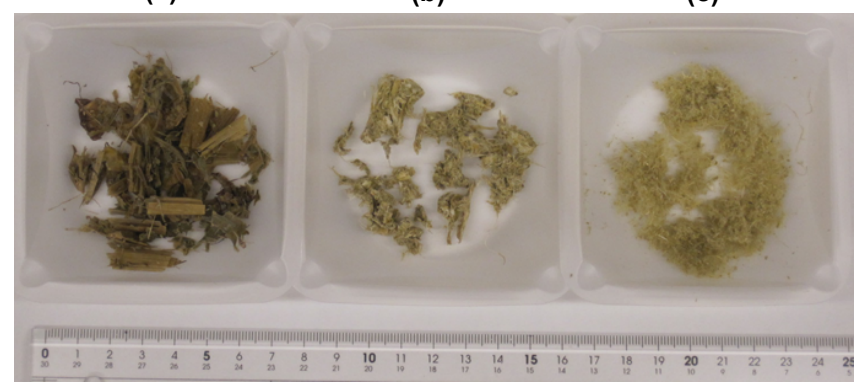

Figure 4: Ensiling corn stover. (a) Raw biomass. $\mathrm{NaOH}$-treated dry biomass before (b) and after grinding operation (c).

in total (Figure 5a). The cells of MITXM-61 were grown using a filtered $90 \%$ solution containing $118 \mathrm{gl}^{-1}$ of initial total sugars composed of 82 $\mathrm{gl}^{-1}$ glucose, $32 \mathrm{gl}^{-1}$ xylose and $4 \mathrm{gl}^{-1}$ arabinose in the bioreactor system. The cell growth increased after 3 days of cultivation (Figure 5b), and the lag phase in the hydrolysate was longer than that in a refined sugar solution containing a similar sugar concentration and composition-a mixture of $80 \mathrm{gl}^{-1}$ glucose and $40 \mathrm{gl}^{-1}$ xylose, $120 \mathrm{gl}^{-1}$ of total sugars (Figure 3). The longer lag phase potentially resulted from certain growth suppressors present in the hydrolysate. However, the depletion of nitrogen and glucose occurred after 4 days, and xylose was depleted after 5 days as xylose and glucose in the hydrolysate were consumed simultaneously. A maximum TAG production as fatty acids of $15.9 \mathrm{gl}^{-1}$, corresponding to $54.0 \%$ of the CDW $\left(29.4 \mathrm{gl}^{-1}\right)$, occurred at 5 days of cultivation (Figure $5 \mathrm{~b}$ ), and the yield of TAGs as fatty acids per gram of 
Citation: Kurosawa K, Wewetzer SJ, Sinskey AJ (2014) Triacylglycerol Production from Corn Stover Using a Xylose-Fermenting Rhodococcus opacus Strain for Lignocellulosic Biofuels. J Microb Biochem Technol 6: 254-259. doi:1.4172/1948-5948.1000153

(a)

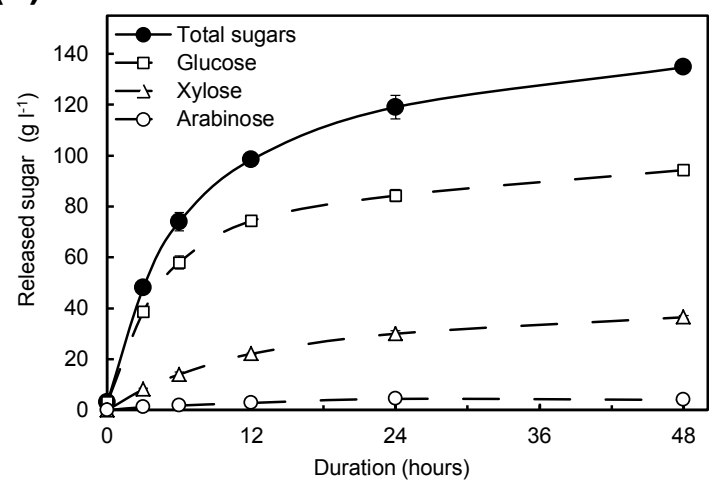

(c)

\begin{tabular}{lccc}
\hline \multirow{2}{*}{ Fatty acid species } & $\begin{array}{c}\text { Corn stover } \\
\text { hydrolysate }\end{array}$ & \multicolumn{2}{c}{ Defined medium } \\
\cline { 3 - 4 } & $2.0( \pm 0.0)$ & $2.3( \pm 0.1)$ & $2.1( \pm 0.0)$ \\
\hline Myristic acid (C14:0) & $5.0( \pm 0.0)$ & $5.9( \pm 0.1)$ & $6.4( \pm 0.1)$ \\
Pentadecanoic acid (C15:0) & $29.7( \pm 0.6)$ & $27.7( \pm 0.4)$ & $27.5( \pm 0.3)$ \\
Palmitic acid (C16:0) & $9.7( \pm 0.6)$ & $13.6( \pm 0.8)$ & $11.9( \pm 0.2)$ \\
Palmitoleic acid (C16:1) & $9.0( \pm 0.0)$ & $7.7( \pm 0.5)$ & $9.5( \pm 0.1)$ \\
Heptadecanoic acid (C17:0) & $14.7( \pm 0.6)$ & $16.9( \pm 0.3)$ & $17.4( \pm 0.1)$ \\
cis-10-Heptadecenoic acid (C17:1) & $5.0( \pm 0.0)$ & $3.0( \pm 0.1)$ & $3.5( \pm 0.0)$ \\
Stearic acid (C18:0) & $24.3( \pm 0.6)$ & $23.0( \pm 0.4)$ & $20.0( \pm 0.2)$ \\
Oleic acid (C18:1) & & &
\end{tabular}

(b)
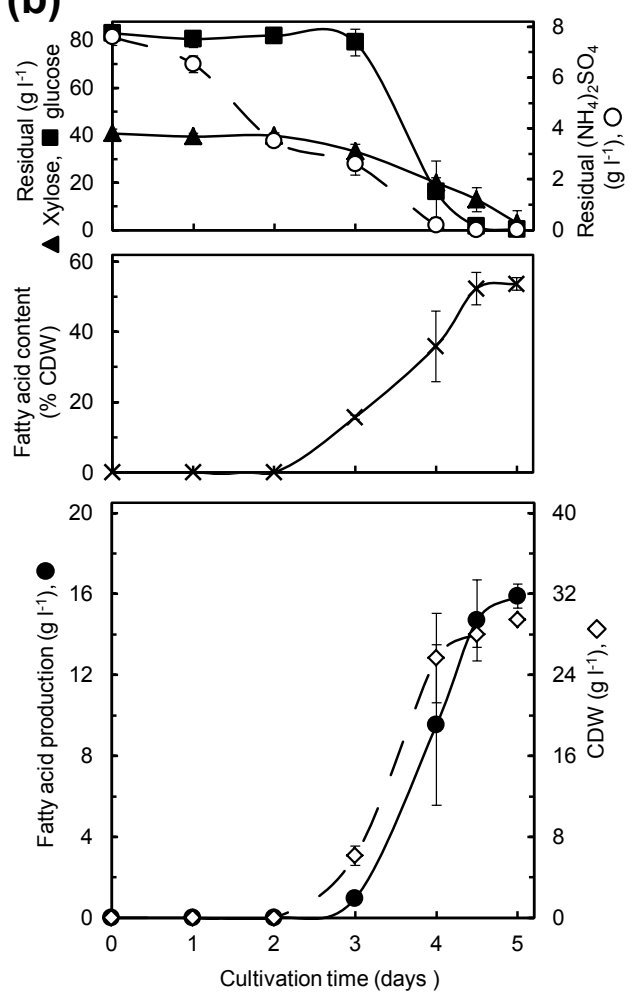

Figure 5: TAG production from corn stover hydrolysate by R. opacus MITXM-61 in batch-culture fermentations. (a) Hydrolysis of ensiling corn stover using a commercially available enzyme cocktail. A hundred grams of the pretreated dry biomass and $10 \mathrm{~g}$ of $\mathrm{CTec} 2$ enzyme were mixed with a desired volume of 0.002 $\mathrm{N} \mathrm{HCl}$ to reach a total volume of 1 liter and a pH of 5.0 . The reaction was carried out in a shaker at $45^{\circ} \mathrm{C}, 200 \mathrm{rpm}$. After 3 and $6 \mathrm{~h}$ of duration, additional $50 \mathrm{~g}$ of the pretreated dry biomass was added into the suspension twice. (b) Time course kinetics of TAG production on the corn stover hydrolysate in Bioengineeringbioreactor cultivations. MITXM-61 was inoculated in the hydrolysate containing $118 \mathrm{gl}^{-1}$ of total sugars composed of $82 \mathrm{gl}^{-1} \mathrm{glucose} 32 \mathrm{gl}^{-1} \mathrm{xylose}^{-}$and $4 \mathrm{gl}^{-1}$ arabinose supplemented with $6.7 \mathrm{gl}^{-1}\left(\mathrm{NH}_{4}\right)_{2} \mathrm{SO}_{4}$ and mineral components of defined medium. (c) Fatty acids composition profile as \% of total fatty acids ( $\mathrm{g} \mathrm{g}^{-1}$ ) of TAGs from R. opacus MITXM-61 cells growing in the corn stover hydrolysate for 5 days in (b) and defined medium containing xylose for 5 days in Figure $2 c$ or xylose/glucose mixture for 3 days in Figure 3. Data are results of triplicate experiments, \pm s.d.

sugars consumed was $0.139 \mathrm{~g}$ with a productivity of $0.133 \mathrm{gl}^{-1} \mathrm{~h}^{-1}$. Fatty acid composition profiles as $\%$ of total fatty acid of the TAGs from cultures containing corn stover hydrolysate and those containing the refined sugars of xylose or xylose/glucose mixes are shown (Figure 5c). The results were analyzed when fatty acid production in each condition reached its maximum state in the range of 15.8 to $16.9 \mathrm{gl}^{-1}$. Fatty acid profiles under these conditions were very similar, and the accumulated fatty acids consisted primarily of palmitic acid (27 to $30 \%$ ), oleic acid (20 to $25 \%$ ) and cis-10-heptadecenoic acid (14 to $18 \%$ ).

\section{Conclusions}

R. opacus MITXM-61 harbors a rare xylose-fermenting trait, capable of completely and simultaneously utilizing mixed sugars of glucose and xylose at high concentrations greater than $120 \mathrm{gl}^{-1}$ in genuine lignocellulosic hydrolysate from corn stover and producing large amounts of TAGs as a precursor for hydrocarbon-based biofuels. Bioethanol commercialization will eventually be the process of building an industry out of methods of turning lignocellulosic biomass into fuel. Despite substantial endeavors, the microbial technology to efficiently convert the high concentrations of glucose and xylose present in lignocellulosic hydrolysates to ethanol still represents a challenge to fully unlock its commercial future. We conclude that an oleaginous bacterium, $R$. opacus MITXM-61, possesses the significant characteristics to formulate a new industrially-relevant strategy for developing hydrocarbon-based lignocellulosic biofuels.

\section{Acknowledgements}

This work was supported by grant HR0011-10-C-0187 from the Defense Advanced Research Projects Agency, Logos Technologies, Inc., the MIT Energy Initiative and Sweetwater Energy, Inc. The strategy described in this study is included in U.S. patent application $(13 / 655,897)$. We thank Christopher J. Brigham for valuable discussion and a review of the manuscript, and C. Anthony Debono for technical assistances.

\section{References}

1. Ragauskas AJ, Williams CK, Davison BH, Britovsek G, Cairney J, et al. (2006) The path forward for biofuels and biomaterials. Science 311: 484-489.

2. Fairley $P(2011)$ Introduction: Next generation biofuels. Nature 474: S2-5.

3. Regalbuto JR (2009) Engineering. Cellulosic biofuels-got gasoline? Science 325: $822-824$

4. Peralta-Yahya PP, Keasling JD (2010)Advanced biofuel production in microbes Biotechnol J 5: 147-162.

5. Lestari S, Mäki-Arvela P, Beltramini J, Lu GQ, Murzin DY (2009) Transforming triglycerides and fatty acids into biofuels. Chem Sus Chem 2: 1109-1119.

6. Santillan-Jimenez E, Crocker M (2012) Catalytic deoxygenation of fatty acids and their derivatives to hydrocarbon fuels via decarboxylation/decarbonylation. J Chem Technol Biotechnol 87: 1041-1050. 
Citation: Kurosawa K, Wewetzer SJ, Sinskey AJ (2014) Triacylglycerol Production from Corn Stover Using a Xylose-Fermenting Rhodococcus opacus Strain for Lignocellulosic Biofuels. J Microb Biochem Technol 6: 254-259. doi:1.4172/1948-5948.1000153

7. Furimsky E (2013) Hydroprocessing challenges in biofuels production. Catal Today 217: 13-56.

8. Pearlson M, Wollersheim C, Hileman J (2013) A techno-economic review of hydroprocessed renewable esters and fatty acids for jet fuel production. Biofuels Bioprod Bioref 7: 89-96.

9. D7566 A (2014) Specification for aviation turbine fuel containing synthesized hydrocarbons.

10. Murphy DJ (2001) The biogenesis and functions of lipid bodies in animals, plants and microorganisms. Prog Lipid Res 40: 325-438.

11. Hu Q, Sommerfeld M, Jarvis E, Ghirardi M, Posewitz M, et al. (2008) Microalga triacylglycerols as feedstocks for biofuel production: perspectives and advances. Plant J 54: 621-639.

12. Singh A, Nigam PS, Murphy JD (2011) Mechanism and challenges in commercialisation of algal biofuels. Bioresour Technol 102: 26-34.

13. Waltz E (2013) Algal biofuels questioned. Nat Biotechnol 31: 12

14. Kosa M, Ragauskas AJ (2011) Lipids from heterotrophic microbes: advances in metabolism research. Trends Biotechnol 29: 53-61.

15. Alper H, Stephanopoulos G (2009) Engineering for biofuels: exploiting innate microbial capacity or importing biosynthetic potential? Nat Rev Microbiol 7: 715-723.

16. Peralta-Yahya PP, Zhang F, del Cardayre SB, Keasling JD (2012) Microbial engineering for the production of advanced biofuels. Nature 488: 320-328.

17. Hu C, Wu S, Wang Q, Jin G, Shen H, et al. (2011) Simultaneous utilization of glucose and xylose for lipid production by Trichosporon cutaneum. Biotechnol Biofuels 4: 25

18. Demeke MM, Dietz H, Li Y, Foulquié-Moreno MR, Mutturi S, et al. (2013) Development of a D-xylose fermenting and inhibitor tolerant industria Saccharomyces cerevisiae strain with high performance in lignocellulose hydrolysates using metabolic and evolutionary engineering. Biotechnol Biofuels 6: 89.

19. Dellomonaco C, Fava F, Gonzalez R (2010) The path to next generation biofuels: successes and challenges in the era of synthetic biology. Microb Cell Fact 9: 3 .

20. Kim SR, Skerker JM, Kang W, Lesmana A, Wei N, et al. (2013) Rational and evolutionary engineering approaches uncover a small set of genetic changes efficient for rapid xylose fermentation in Saccharomyces cerevisiae. PLoS One 8: e57048

21. Krahulec S, Petschacher B, Wallner M, Longus K, Klimacek M, et al. (2010) Fermentation of mixed glucose-xylose substrates by engineered strains of Saccharomyces cerevisiae: role of the coenzyme specificity of xylose reductase, and effect of glucose on xylose utilization. Microb Cell Fact 9: 16.

22. Wältermann M, Luftmann H, Baumeister D, Kalscheuer R, Steinbüchel A (2000)
Rhodococcus opacus strain PD630 as a new source of high-value single-cell oil? Isolation and characterization of triacylglycerols and other storage lipids. Microbiology 146 : 1143-1149.

23. Kurosawa K, Boccazzi P, de Almeida NM, Sinskey AJ (2010) High-cell-density batch fermentation of Rhodococcus opacus PD630 using a high glucose concentration for triacylglycerol production. J Biotechnol 147: 212-218.

24. Kurosawa K, Wewetzer SJ, Sinskey AJ (2013) Engineering xylose metabolism in triacylglycerol-producing Rhodococcus opacus for lignocellulosic fuel production. Biotechnol Biofuels 6: 134.

25. Somerville C, Youngs H, Taylor C, Davis SC, Long SP (2010) Feedstocks for lignocellulosic biofuels. Science 329: 790-792.

26. Gramig BM, Reeling CJ, Cibin R, Chaubey I (2013) Environmental and economic trade-offs in a watershed when using corn stover for bioenergy. Environ Sci Technol 47: 1784-1791.

27. Kaliyan N, Morey RV (2009) Densification characteristics of corn stover and switchgrass. Transactions of the ASABE 52: 907-920.

28. Xu J, Zhang X, Cheng JJ (2012) Pretreatment of corn stover for sugar production with switchgrass-derived black liquor. Bioresour Technol 111: 255-260.

29. Keshwani DR, Cheng JJ (2010) Microwave-based alkali pretreatment of switchgrass and coastal bermudagrass for bioethanol production. Biotechnol Prog 26: 644-652.

30. Zhang X, Xu J, Cheng JJ (2011) Pretreatment of corn stover for sugar production with combined alkaline reagents. Energy Fuels 25: 4796-4802.

31. Templeton DW, Sluiter AD, Hayward TK, Hames BR, Thomas SR (2009) Assessing corn stover composition and sources of variability via NIRS. Cellulose 16: 621-639.

32. Graham RL, Nelson R, Sheehan J, Perlack RD, Wright LL (2007) Current and potential US corn stover supplies. Agron J 99: 1-11.

33. Wilhelm WW, Johnson JME, Karlen DL, Lightle DT (2007) Corn stover to sustain soil organic carbon further constrains biomass supply. Agron J 99: 1665-1667.

34. Sluiter A, Hames B, Ruiz R, Scarlata C, Sluiter J, et al. (2008) Determination of structural carbohydrates and lignin in biomass: laboratory analytical procedure. Golden, CO: Technical Report NREL/TP-510-42618.

35. Riesenberg D, Guthke R (1999) High-cell-density cultivation of microorganisms. Appl Microbiol Biotechnol 51: 422-430.

36. Avci A, Saha BC, Dien BS, Kennedy GJ, Cotta MA (2013) Response surface optimization of corn stover pretreatment using dilute phosphoric acid for enzymatic hydrolysis and ethanol production. Bioresour Technol 130: 603-612.

37. Ren H, Richard TL, Chen Z, Kuo M, Bian Y, et al. (2006) Ensiling corn stover: effect of feedstock preservation on particleboard performance. Biotechnol Prog 22: $78-85$. 